\title{
Adjunct Use of Low-Level Laser Therapy on the Treatment of Necrotizing Ulcerative Gingivitis: A Case Report
}

\author{
Seda Sevinç Özberk' ${ }^{1}$, Hasan Gündoğar², Süleyman Ziya Şenyurt² ${ }^{2}$, Kamile Erciyas ${ }^{2}$ \\ ${ }^{1}$ Ministry of Health, Republic of Turkey, Gaziantep, Turkey \\ ${ }^{2}$ Periodontology Department, Faculty of Dentistry, Gaziantep University, Gaziantep, Turkey
}

\author{
*Correspondence to \\ Hasan GÜNDOĞAR, Periodontology \\ Department, Faculty of Dentistry, \\ Gaziantep University, Gaziantep, \\ Turkey. \\ Tel: +90 5052793080; \\ Email: hgundogar@gmail.com
}

Published online 26 December 2017

\section{Introduction}

Necrotizing ulcerative gingivitis (NUG) is a type of necrotizing periodontal disease. It is a painful periodontal disease limited to the gingival tissues and characterized by red, ulcerated gingivae, oral malodor and "punchedout" interdental papillae. ${ }^{1,2}$

The prevalence of NUG appears to have been rather low in the United States and Europe before 1914. ${ }^{3}$ NUG generally affects females and males equally, at all ages, presenting most commonly in 18-30-year-old patients. ${ }^{2}$ The etiology of NUG is not known. Its presence causes a great increase in fusiform bacilli and spirochetes, and the clinical signs of this disease have been attributed to this increase in the fusospirochetal complexes, and other bacilli. ${ }^{4}$

NUG generally begins with increased psychological stress, increased physical demands, a decreased nutrient intake, smoking, and, especially, bacterial plaque. ${ }^{1}$ Pain (usually rapid onset), interdental necrosis, and bleeding are the specific clinical symptoms to diagnose NUG. If one of these 3 symptoms is absent, NUG cannot be diagnosed. Pain is the hallmark of NUG, and this pain affects the patient's quality of life. Generally, patients complain of pain. ${ }^{1}$ Sometimes, systemic symptoms like fever, malaise, and both cervical and submandibular lymphadenopathy can accompany NUG. ${ }^{2}$

Conventional treatment of NUG aims to eliminate the acute inflammation by reducing microbial dental plaque, and removing necrotic tissue. If patients have systemic symptoms related to NUG, antibiotics are recommended. ${ }^{3}$ Low-level laser therapy (LLLT) is the application of light to increase tissue healing, reduce inflammation, and offer pain control. ${ }^{5}$ LLLT is used in different dental procedures, such as nonsurgical and surgical periodontal treatments, and in many clinical conditions, such as temporomandibular disorders, hypersensitive dentine, post-extraction and bone-healing therapy, traumatic ulcerations, herpes simplex virus infection of the lips, aphthous ulcers, mucositis, paresthesiae, and trigeminal neuralgia. ${ }^{6}$ The biostimulative effects of LLLT have been 
shown in the literature, and LLLT is indicated in cases of pain and tissue healing. ${ }^{7}$ Pain reduction is among the claimed effects of LLLT. ${ }^{8}$ In this case report, we aimed to show a rare NUG case treated with adjunct use of LLLT.

\section{Case Presentation}

A 34-year-old, systemically healthy, heavy-smoker, male patient was referred to our department with severe pain. Clinical and radiographic examination showed clinical attachment loss and poor oral hygiene. A clinical diagnosis of NUG was made (Figure 1A). First of all, we removed the pseudomembrane with a hydrogen peroxide cotton roll (Figure 1B). The patient received $500 \mathrm{mg}$ amoxicillin and $400 \mathrm{mg}$ metronidazole 3 times a day for 5 days, and chlorhexidine $0.2 \%$ mouthwash twice a day, for the treatment of his necrotizing gingivitis. On the second visit, scaling and root planing was performed, after which laser was performed at 2,3,5, and 9 days as an adjunct to conventional NUG treatment (Figure 1C). LLLT was applied with a $980 \mathrm{~nm}$ diode laser, that was set $0.4 \mathrm{~W}$, continuous wave (CW), energy density was $9 \mathrm{~J} / \mathrm{cm}^{2}$, for 60 seconds in non-contact but very close to the tissue, distance was approximately 1-2 mm, using LLLT tips. After LLLT, there were no adverse effects. The patient showed spontaneous relief of pain and was carefully followed up until complete healing occurred, with no complications documented. After 5 weeks, we performed a gingivectomy procedure (Figure 1D).

\section{Discussion}

NUG is a severe inflammatory periodontal disease caused by the proliferation of plaque bacteria associated with a diminished host defense. In NUG, loss of clinical attachment and alveolar bone are very rare findings, but patients can have NUG after periodontal disease. ${ }^{1}$

NUG has 3 specific clinical findings. These are pain, interdental necrosis, and gingival bleeding. Pain has long been among the most significant effects of NUG and affects the patients' quality of life. Generally, pain is the major factor in patient referral for treatment. ${ }^{1}$

NUG treatment involves the alleviation of acute inflammation by removing microbial dental plaque and necrotic tissue. If patients have systemic symptoms like fever, oral malodor, or lymphadenopathy, then prescribing medicine $^{3}$ and analgesics remains the principal option for the management of NUG pain. However, analgesics (such as non-steroidal anti-inflammatory drugs [NSAIDs]) have common adverse effects, such as allergies, gastric ulcers, and bleeding disorders, for which reason they are not widely used in clinical practice. ${ }^{9}$

The adjunct use of LLLT in the treatment of various diseases has increased gradually during the last ten years. ${ }^{10}$ It has been demonstrated in the literature that LLLT stimulates wound healing without adverse effects and has a relieving role. Anti-inflammatory and especially analgesic
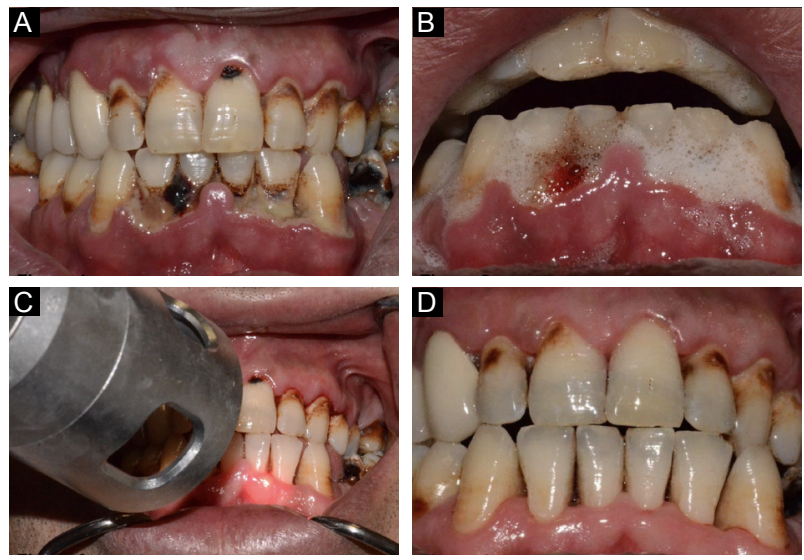

Figure 1. (A) Clinical Examination. (B) Application of $\mathrm{H}_{2} \mathrm{O}_{2}$. (C) Application of LLLT. (D) Final Situation.

effects of the use of LLLT in dentistry have frequently been investigated. Furthermore, there have been the clinical reflections of studies on temporomandibular joint disorders, dentine hypersensitivity, the use of LLLT in addition to orthodontic treatment and after the extraction of impacted wisdom tooth. ${ }^{11}$ Some of these studies have focused on the analgesic effect after periodontal treatments. In the study carried out by Masse et al, ${ }^{12}$ it was emphasized that LLLT administered after free gingival graft does not have a pain-relieving effect. However, Tomasi et $\mathrm{al}^{13}$ concluded that the administration of LLLT after periodontal treatment decreases the pain. There is a limited number of studies on the clinical use of LLLT as pain reliever. ${ }^{14}$ This case report emphasizes that the use of LLLT, which is a non-pharmacological technique and does not have any side effect, in NUG patients, may be good, especially in terms of patient comfort and healing speed. ${ }^{11}$

Our case report shows that the use of LLLT as an adjunct to conventional NUG treatment reduces the use of analgesic, anti-inflammatory drugs, and accelerates healing, with the purpose of improving the quality of life for these patients. The use of LLLT in adjunct to NUG treatment can be used with the aim of reducing pain and accelerating wound healing. However, multicenter randomized controlled trials are needed even though it is a rare case.

\section{Conflict of Interests}

The authors have no conflict of interest to declare.

\section{Ethical Considerations}

Written informed consent was obtained from the patient for publishing this case report.

\section{References}

1. Rowland RW. Necrotizing ulcerative gingivitis. Ann Periodontol. 1999;4(1):65-73; discussion 78. doi:10.1902/ 
annals.1999.4.1.65

2. Sangani I, Watt E, Cross D. Necrotizing ulcerative gingivitis and the orthodontic patient: a case series. J Orthod. 2013;40(1):77-80. doi:10.1179/1465313312y.0000000037

3. Newman MG, Takei H, Klokkevold PR, Carranza FA. Carranza's Clinical Periodontology. 12th ed. Philadelphia, PA: Elsevier; 2014.

4. Shannon IL, Kilgore WG, O'Leary TJ. Stress as a Predisposing Factor in Necrotizing Ulcerative Gingivitis. J Periodontol. 1969;40(4):240-242. doi:10.1902/ jop.1969.40.4.240

5. Carroll JD, Milward MR, Cooper PR, Hadis M, Palin WM. Developments in low level light therapy (LLLT) for dentistry. Dent Mater. 2014;30(5):465-475. doi:10.1016/j. dental.2014.02.006

6. Misra N, Chittoria N, Umapathy D, Misra P. Efficacy of diode laser in the management of oral lichen planus. BMJ Case Rep. 2013;2013. doi:10.1136/bcr-2012-007609

7. Gasperini G, Rodrigues de Siqueira IC, Rezende Costa L. Does low-level laser therapy decrease swelling and pain resulting from orthognathic surgery? Int J Oral Maxillofac Surg. 2014;43(7):868-873. doi:10.1016/j.ijom.2014.02.015

8. Vallone F, Benedicenti S, Sorrenti E, Schiavetti I, Angiero F. Effect of diode laser in the treatment of patients with nonspecific chronic low back pain: a randomized controlled trial. Photomed Laser Surg. 2014;32(9):490-494. doi:10.1089/pho.2014.3715

9. Ren C, McGrath C, Yang Y. The effectiveness of low-level diode laser therapy on orthodontic pain management: a systematic review and meta-analysis. Lasers Med Sci. 2015;30(7):1881-1893. doi:10.1007/s10103-015-1743-4

10. Minicucci EM, Miot HA, Barraviera SR, Almeida-Lopes L. Low-level laser therapy on the treatment of oral and cutaneous pemphigus vulgaris: case report. Lasers Med Sci. 2012;27(5):1103-1106. doi:10.1007/s10103-012-1101-8

11. Sanz-Moliner JD, Nart J, Cohen RE, Ciancio SG. The effect of an 810-nm diode laser on postoperative pain and tissue response after modified Widman flap surgery: a pilot study in humans. J Periodontol. 2013;84(2):152-158. doi:10.1902/ jop.2012.110660

12. Masse JF, Landry RG, Rochette C, Dufour L, Morency R, D’Aoust P. Effectiveness of soft laser treatment in periodontal surgery. Int Dent J. 1993;43(2):121-127.

13. Tomasi C, Schander K, Dahlen G, Wennstrom JL. Short-term clinical and microbiologic effects of pocket debridement with an Er:YAG laser during periodontal maintenance. J Periodontol. 2006;77(1):111-118. doi:10.1902/jop.2006.77.1.111

14. Artes-Ribas M, Arnabat-Dominguez J, Puigdollers A. Analgesic effect of a low-level laser therapy (830 $\mathrm{nm})$ in early orthodontic treatment. Lasers Med Sci. 2013;28(1):335-341. doi:10.1007/s10103-012-1135-y 